\title{
Apparent Enlargement of the Sun at the time of Rising and Setting By Dr. Vaughan Cornish
}

$\mathrm{T}$ is a matter of common observation that when 1 the sun is nearly on a level with the eye and is in the vicinity of the horizon its apparent size

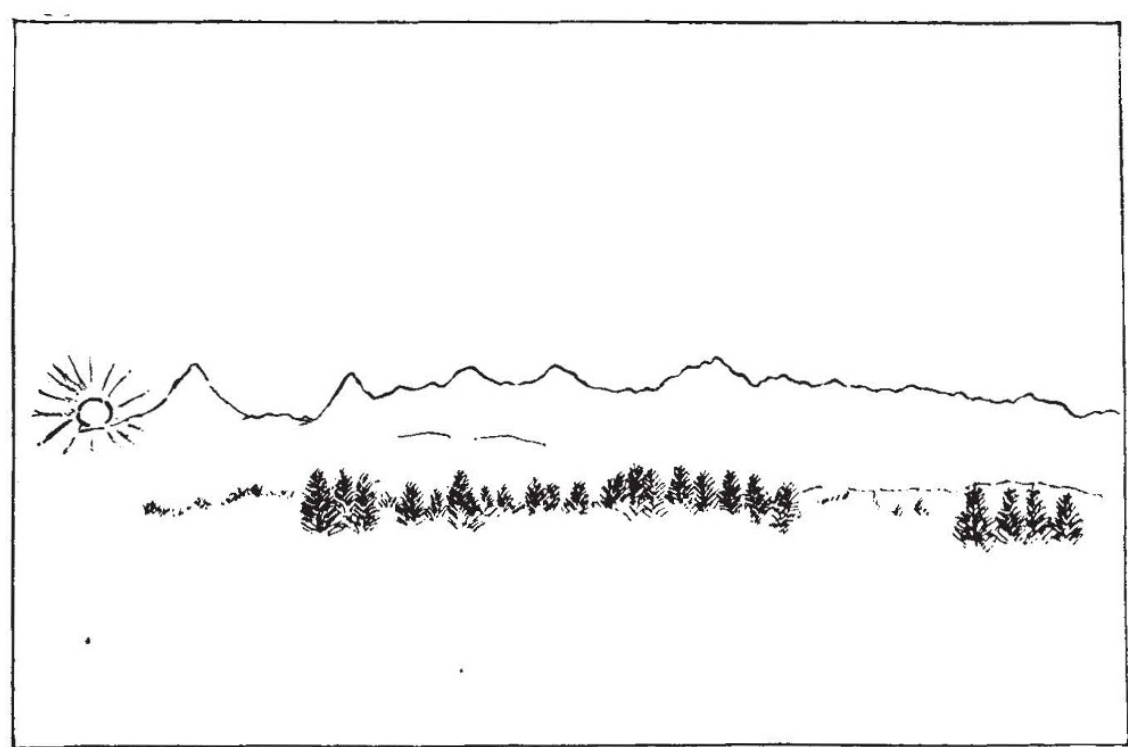

Fig. 1.

The Rising SUn from Bern ment, or any intention of subsequent measurement, but from known view-points, so that the angular magnitudes of terrestrial features were afterwards ascertained from the map.

The sun seen from Bern rising above the Bernese Alps forty miles away, measured $0 \cdot 16$ inch on a 7 -inch page. As seen from Grindelwald the sun rising above the Wetterhorn four miles away measured only 0.9 inch on a 7 -inch page. These measurements seem at first to confirm the expectation that the sun would be apparently enlarged in proportion to the diminution of terrestrial features by greater distance. When, however, I measured the mountains in the two drawings and compared is greater than when high up in the sky. It is them with the distances as measured on the map, generally assumed that this is due to the circum. I found that the apparent magnitude in the more stance that the features of the skyline provide a true standard of instinctive comparison which enables the eye to appreciate the angle subtended by the sun's disk. It is true that the linear magnitude of the terrestrial features is fairly well known and that the tone and other qualities of the horizon give an instinctive impression of its distance. The current explanation breaks down, however, under the test of actual measurement of the apparent magnitudes. These measurements are trustworthy only if made by an indirect method which sidetracks the critical faculty, for as soon as thought comes into play, the spontaneous impression of magnitude is impaired. The measurements in question have been made from a number of sketches which I have made during the last forty years, all drawn originally without measure-

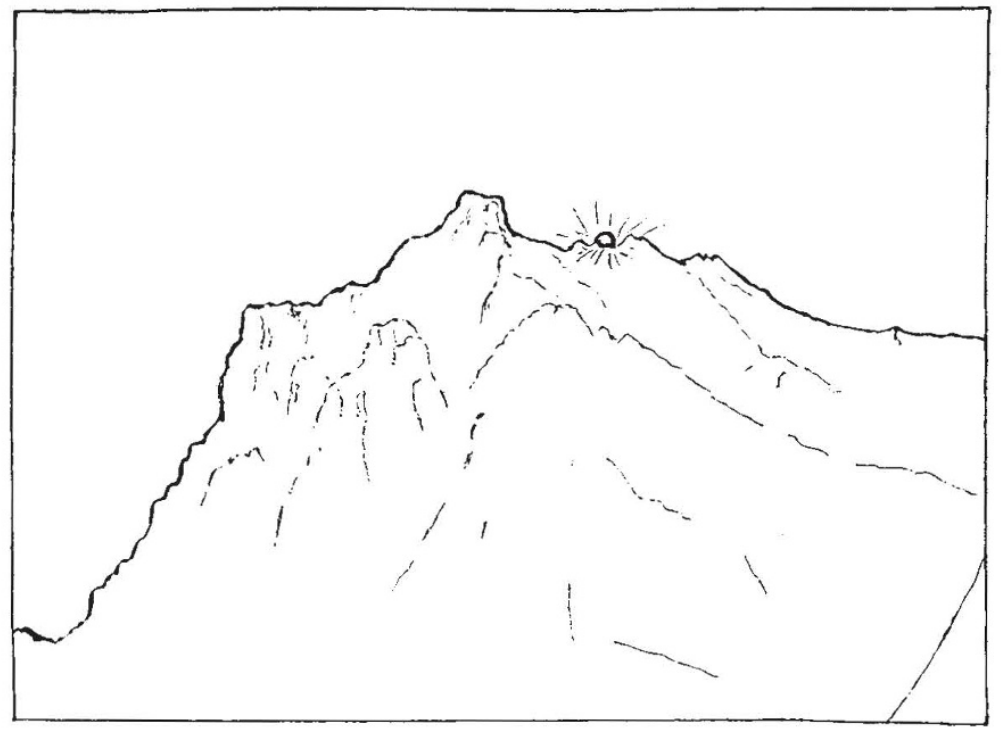

Fig. 2.

The Rising Sun from Grindelwald

distant view was not reduced proportionately to the distance, but on the contrary was subjectively 
magnified. The are of horizon comprised in the sketch made at Grindelwald was $34^{\circ}$; that from Bern, $21^{\circ}$. Thus the subjective enlargement of the mountains seen from Bern was $\mathbf{1 \cdot 6}$, that of the sun being $1 \cdot 7$, which for this class of observation is practically identical.

Following up this clue, I measured drawings of the arc of the horizon included in a page of my sketch-book when drawing the long line of comparatively low hills on the west of Bournemouth Bay, and the lofty mountains enclosing the valley of Lauterbrunnen. I found that whereas the impression of lateral extent received in the former case was the greater, the arc of the horizon comprised in the panoramic sketch was much less, that is, the eye was sooner satisfied when it had to deal mainly with one dimension.

Referring again to the small apparent size of the sun when rising above a crest-line something like $20^{\circ}$ above the line of sight, that is, above the Wetterhorn seen from Grindelwald, it will be noted that the features of the view are not strung out in a narrow horizontal band as when the range of which the Wetterhorn is a member is viewed from Bern forty miles away. It seems, therefore, that the more the eye takes in vertically the more it takes in horizontally and the less imposing are both dimensions.

These indications led to an interesting result on measuring drawings which comprised the peaks of Eiger and Mönch seen from Gurten-Kulm and from Kleine Scheidegg, distant respectively about 37 and $2 \frac{1}{2}$ miles. From the former position, the arc of the horizon in the page of the sketch-book was $18 \frac{1}{2}^{\circ}$; in the latter $60 \frac{1}{2}^{\circ}$. The peaks seen from Kleine Scheidegg stood about $26^{\circ}-27^{\circ}$ above the line of sight. These measurements explain the familiar sense of disappointment experienced on near approach to mountain peaks the great magnitude of which has impressed the mind when viewed from a distance. As we approach the mountain the field of attention steadily expands without, however, any warming sensation in the eye. Our field of attention varies according to circumstances and the mind transfers the change of magnitude to the objects in the field, but in the reversed sense, an actual restriction of the field being accompanied by apparent enlargement of the objects viewed.

\section{Expedition to Baffin Bay, I937}

$\mathrm{A}^{\mathrm{N}}$ expedition, led by J. M. Wordie of St. John's College, Cambridge, has returned from a three months voyage to Davis Strait and Baffin Bay. The party, ten in number, had as its main objectives the geology and archæology of Ellesmere Land and the investigation of the upper atmosphere by free balloons. The Norwegian motor-sealing vessel Isbjørn, of Tromsø, 172 tons, carrying a crew of twelve, was specially chartered for the expedition, and sailed from Leith on June 27, returning on October 1 . H. Carmichael and E. G. Dymond, who was assisted by I. M. Hunter, made cosmic ray investigations with high-altitude balloons near the magnetic pole. Eskimo anthropology and archæology were studied by T. C. Lethbridge and T. T. Paterson, assisted by R. W. Feachem and D. Leaf; geology, petrology and physiography by Paterson, H. I. Drever and A. H. Robin ; and botany by Feachem.

The year was exceptional in that no ice was met with in Melville Bay, and the ship was able to proceed as far north as Bache Peninsula in Ellesmere Land without ice hindrance; the Middle Pack, which usually occupies the west side of Baffin Bay, and is fed from Smith Sound and
Lancaster Sound, was nowhere seen. This lack of ice, though it gave unusual opportunities for archæological work and geographical exploration, had the disadvantage that no large floes were available out at sea as launching grounds for balloon flights, and cosmic ray work was therefore confined to the West Greenland coast.

The cosmic ray experiments involved the measurement of the intensity of the radiation at great altitudes in the polar atmosphere, and instruments were conveyed to heights of more than $25 \mathrm{~km}$. by free balloons, utilizing the methods of Prof. E. Regener of Stuttgart. Two types of apparatus were used, one designed and constructed by Carmichael in the Cavendish Laboratory, Cambridge, consisting of a pressure ionization chamber and electrometer with photographic recording of the ionization, pressure and temperature, and the other, by Dymond in Edinburgh and J. A. Ratcliffe in Cambridge, a triple-coincidence counting set with wireless transmission of the counts and the barometric pressure. In addition, the intensity of the cosmic rays at sealevel was recorded by two ionization instruments, one lent to the expedition by Regener and Hoerlin, 